Purdue University

Purdue e-Pubs

2009

\title{
Measurement and Prediction of the Cooling Characteristics of a Generalized Vibrating Piezoelectric Fan
}

\author{
Mark L. Kimber \\ S V. Garimella \\ Purdue University, sureshg@purdue.edu
}

Follow this and additional works at: http://docs.lib.purdue.edu/coolingpubs

\footnotetext{
Kimber, Mark L. and Garimella, S V., "Measurement and Prediction of the Cooling Characteristics of a Generalized Vibrating Piezoelectric Fan" (2009). CTRC Research Publications. Paper 118.

http://dx.doi.org/10.1016/j.ijheatmasstransfer.2009.03.055
}

This document has been made available through Purdue e-Pubs, a service of the Purdue University Libraries. Please contact epubs@purdue.edu for additional information. 


\title{
Measurement and Prediction of the Cooling Characteristics of a Generalized Vibrating Piezoelectric Fan ${ }^{1}$
}

\author{
Mark Kimber and Suresh V. Garimella ${ }^{2}$ \\ Cooling Technologies Research Center \\ School of Mechanical Engineering and Birck Nanotechnology Center, Purdue University \\ 585 Purdue Mall, West Lafayette, IN 47907-2088 USA \\ (765) 494-5621, sureshg@purdue.edu
}

\begin{abstract}
Piezoelectric fans are thin elastic beams whose vibratory motion is actuated by means of a piezoelectric material bonded to the beam. These fans have found use as a means to enhance convective heat transfer while requiring only small amounts of power. The objective of the present work is to quantify the influence of each operational parameter and its relative impact on thermal performance. Of particular interest are the vibration frequency and amplitude as well as the geometry of the vibrating cantilever beam. The experimental setup consists of a piezoelectric fan mounted normal to a constant heat flux surface. Temperature contours on this surface captured via an infrared camera are used to extract the forced convection coefficient due to the fluid motion generated from the fan. Different fans, with fundamental resonance frequencies ranging from 60 to $250 \mathrm{~Hz}$, are considered. Results show that the performance of the fans is maximized at a particular value of the gap between the fan tip and the heated surface. It is found that when a fan operates at this optimum gap, the heat transfer rate is dependent only on the frequency and amplitude of oscillation. Correlations based on appropriately defined dimensionless parameters are developed and found to successfully predict the thermal performance across the entire range of fan dimensions, vibration frequency and amplitude. An understanding of the dependence of thermal performance on the governing variables allows for improved design of piezoelectric fans as a method of enhancing heat transfer.
\end{abstract}

Keywords: piezoelectric fans, vibrating cantilevers, heat transfer enhancement

\footnotetext{
${ }^{1}$ Submitted for publication in International Journal of Heat and Mass Transfer, June 2008, and in revised form, March 2009.

${ }^{2}$ Author to whom correspondence should be addressed: 765-494-5621, sureshg@purdue.edu
} 


\section{Nomenclature}

A vibration amplitude

$\mathrm{A}_{\text {heat }} \quad$ area of heat source

D piezoelectric fan width

G gap between fan tip and heat source

h local convection coefficient

$\overline{\mathrm{h}} \quad$ area-averaged convection coefficient

$\mathrm{I}_{\mathrm{s}} \quad$ current supplied to heater from power supply

$\mathrm{k}$ thermal conductivity

$\mathrm{L}_{0} \quad$ overall piezoelectric fan length

$\mathrm{L} \quad$ length of exposed portion of fan blade

$\mathrm{Nu} \quad$ Nusselt number

q" heat flux

Re Reynolds number [Eq. (7)]

Str Strouhal number [Eq. (8)]

$\mathrm{T}_{\mathrm{s}} \quad$ surface temperature

$\mathrm{T}_{\infty} \quad$ ambient temperature

$\mathrm{V}_{\mathrm{s}} \quad$ voltage drop across heater

$\mathrm{x}$ horizontal distance along heat source

y vertical distance along heat source

Greek Symbols

$\gamma \quad$ exponential decay rate of thermal performance from maximum value

$\checkmark \quad$ kinematic viscosity of fluid (air)

$\omega \quad$ fan driving frequency

\section{Subscripts}

mixed mixed convection regime

nc natural convection

$\mathrm{pz} \quad$ forced convection (due to piezoelectric fan)

VE average quantity in vibration envelope

\section{Introduction}

Piezoelectric fans are vibrating beams, disks, or plates whose vibratory motion is actuated using a piezoelectric material. They can consist of a flexible fan blade to which the piezoelectric element is bonded, or can consist entirely of the piezoelectric material itself. Although the end 
conditions for these fans can vary (e.g., fixed-fixed, fixed-free, etc.), the general concept is the same: an alternating input signal to the piezoelectric element forces oscillations throughout the beam, which can be used to induce flow in the surrounding fluid and provide heat transfer enhancement. As these devices typically run at resonance (most often, the fundamental resonance frequency), significant vibration amplitudes are achieved with only small amounts of input power. These fans also require very little space and therefore are good candidates for low-profile applications or when only limited volume is available. It is also worth noting that if operating frequencies are either low enough or high enough, these devices produce little or no audible noise. As a result of their unique advantages, there has been a surge in recent interest in these devices and they are finding their way into commercial products.

Vibration coupled with heat transfer has been widely investigated in the literature. Studies have focused both on flow-induced vibration and vibration-induced flow. The presence of eddies in internal turbulent flow, or bubble formation in two-phase flow, has been observed to cause vibration of the structure, which affects the heat transfer characteristics. Understanding the effect of vibration is critical in two-phase nuclear reactors [1,2] as well as in heat exchangers [3-5] where vibration is driven by an engine or compressor. Thermal characteristics of heated objects oscillating in a fluid have also been studied, and have included geometries that are spherical [6, 7], cylindrical $[8,9]$, or flat-plate [10,11]. Each of these studies [1-11] has reported heat transfer enhancements over baseline natural or forced convection conditions. The similarities may be noted between past studies of a flat heated surface oscillating in a fluid and an unheated beam oscillating past a flat stationary heated surface, the situation encountered with a piezoelectric fan. One important difference is that piezoelectric fans are designed to be driven at their resonance frequency, whereas in most heat exchanger-type applications, operating at or near the resonance frequency of the structure is to be avoided at all costs to prevent catastrophic failure.

One of the first studies dealing exclusively with heat transfer enhancements from piezoelectric fans targeting a heated surface was conducted by Toda [12] who developed simplified models for vibration prediction and flow field behavior. Toda also conducted heat transfer experiments [13] and showed that these fans were able to cool the radiation panel of a power transistor in a TV receiver by $17^{\circ} \mathrm{C}$. The feasibility of incorporating these devices in actual products was addressed by Açıkalın et al. [14]. They experimentally demonstrated that piezofans increased thermal performance by augmenting a traditional rotary fan within a laptop and by enhancing convection within a cell phone. In a commercial laptop, a temperature drop of $6^{\circ} \mathrm{C}$ was obtained with the piezofans over the cooling obtained with the rotary fan alone. Açıkalın et al. [15] also performed a rigorous parametric study of a fan vibrating near a small discrete heat source in order to document the influence of governing parameters such as distance to target, vibration amplitude, and whether or not the fan was operating at resonance. 
Other studies have emphasized the development of models and design tools for comparison to traditional cooling approaches. Direct comparisons of thermal performance to axial fans and natural convection were made by Açıkalın et al. [16]. They concluded that for a given power consumption, piezoelectric fans performed significantly better than axial fans. When compared to a natural convection heat sink, the piezofans were found to require less volume. In order to enable further comparison, experiments were performed by Kimber et al. [17] to determine the pressure and flow rate generated from vibrating cantilevers. Design tools similar to the often-used fan laws were proposed to predict the pressure and flow rate that would be obtained as a function of different variables. Detailed experimental heat transfer characteristics due to flows from vibrating cantilevers were studied by Kimber et al. [18], who also developed models to predict the heat transfer coefficient as a function of vibration amplitude and distance from target. However, the fan geometry and operating frequency were not considered as variables in that study. Cooling performance of fans placed in an array was also explored by Kimber and Garimella [19]. They found the array spacing, or distance between fans, could have a significant effect on the thermal performance of the array. The optimum spacing was found to be approximately 1.5 times the vibration amplitude.

Florio and Harnoy conducted numerical studies $[20,21]$ of the heat transfer rates attainable for different orientations of a vibrating beam with respect to an electronic component. They considered a transversely vibrating beam placed in the center of a channel in the presence of a natural convection flow [20]. They also showed that vibrations from one of the channel walls could also supplement natural convection in the channel [21]. Yang [22] numerically explored the use of a vibrating bar upstream of heated electronic components to enhance heat transfer through vortex generation. The effect of oscillation frequency and amplitude were both considered as variables in the analysis and it was found that an increase of either variable resulted in higher heat transfer rates. Wu and Ro [23] experimentally investigated heat transfer enhancements over natural convection using a fixed-fixed beam vibrating near a heated surface. They found an optimum gap between the vibrating beam and the heat source at which the heat transfer rate was maximized and proposed a correlation by which the heat transfer performance scales as the tip velocity. This correlation implied that both the frequency and amplitude of the beam have a comparable impact on heat transfer. However, only a single frequency was considered (using only one beam) and the influence of frequency was not actually investigated.

While many different configurations are possible in the use of a vibrating beam to cool a heated surface, the most prevalent is that of a cantilever beam. In addition, the direction of vibration with respect to the heat source could be normal or parallel. In the present work, the thermal performance of cantilever fans mounted normal to a flat heat source is investigated. Such a fan is shown in Fig. 1 where the geometric properties of overall length $\left(\mathrm{L}_{0}\right)$, exposed length $(\mathrm{L})$, 
and width (D) are illustrated. The primary contribution of this work relative to that in [18] is that the influence of each variable (fan length, width, frequency, and amplitude) is independently assessed using a large number of different fans, which enables the development of a comprehensive predictive model for the heat transfer performance of a generalized vibrating cantilever.

\section{Experimental Setup and Procedures}

The experimental setup used to quantify the heat transfer distribution is the same as that described in [18]. Only essential details of the setup are provided here. The setup consists of a vertically oriented constant heat flux surface with a piezoelectric fan mounted on a linear stage and positioned normal to the heated surface. The stage on which the fan is mounted enables precise placement of the fan relative to the heat source while a laser displacement sensor (Keyence LKG157) is aimed at the fan tip to capture the in situ vibration signal of the fan. A plexiglass enclosure with length, width and height of $60 \mathrm{~cm} \times 70 \mathrm{~cm} \times 30 \mathrm{~cm}$, respectively, is built around the entire setup to isolate it from extraneous air currents within the laboratory.

A constant flux heated surface is achieved by stretching a thin stainless steel foil over two 25.4 mm-diameter, oxygen-free copper rods, which serve as voltage terminals. The foil experiences joule heating as a voltage is applied between the two copper rods, thereby providing a constant heat flux in the section of foil located between the two copper rods. The foil is $0.051 \mathrm{~mm}$ thick and $101.6 \mathrm{~mm}$ wide. The required potential drop across the copper rods is achieved with a high-current power supply. Spring-loaded bolts are used to accommodate thermal expansion and maintain the heated foil in tension, and a $25.4 \mathrm{~mm}$-thick plexiglass frame holds the heater assembly together and also provides electrical isolation between the two ends of the heater. The copper rods are separated by a distance of $203.2 \mathrm{~mm}$, thereby providing a heated surface area of $101.6 \mathrm{~mm}$ x $203.2 \mathrm{~mm}$. The foil is coated with a thin layer of black paint (Krylon \#1602) for which the emissivity is known to be 0.95 [24]. The side opposite the fans is left open to ambient conditions and an infrared camera (ThermaCAM Merlin) captures thermal images of the contours. A heat transfer coefficient is computed for each pixel in the infrared image according to a flux balance as illustrated in Fig. 2 . The generated flux $\left(\mathrm{q}_{\text {gen }}\right)$ is determined from measurements of the voltage drop across the foil $\left(\mathrm{V}_{\mathrm{s}}\right)$ and the current through the foil $\left(\mathrm{I}_{\mathrm{s}}\right)$ according to:

$$
\mathrm{q}_{\text {gen }}^{\prime}=\frac{\mathrm{V}_{\mathrm{s}} \cdot \mathrm{I}_{\mathrm{s}}}{\mathrm{A}_{\text {heat }}}
$$

where $A_{\text {heat }}$ is the area of the heated surface between the copper rods. A portion of this generated flux is dissipated through radiation from both sides which is quantified from knowledge of the local surface temperature and emissivity. The heat loss due to natural convection on the side opposite the fans is estimated by first conducting numerous experiments with the fans removed from the 
setup, enabling a thorough description of natural convection coefficients as a function of both position and surface temperature. The remaining flux is dissipated as q" mixed from the surface facing the fans, where both natural and forced convection contribute to the heat dissipation. As only the forced convection component (due to fluid motion generated from the piezoelectric fan) is of interest, this is deduced according to a standard mixed convection regime correlation [25]:

$$
\mathrm{Nu}_{\text {mixed }}{ }^{3}=\mathrm{Nu}_{\mathrm{pz}}{ }^{3}+\mathrm{Nu}_{\mathrm{nc}}{ }^{3}
$$

Since the Nusselt numbers $(\mathrm{Nu})$ in this equation are based on the same length scale, the forced convection coefficient $\left(\mathrm{h}_{\mathrm{pz}}\right)$ can be computed according to:

$$
\mathrm{h}_{\mathrm{pz}}=\left(\mathrm{h}_{\text {mixed }}{ }^{3}-\mathrm{h}_{\mathrm{nc}}{ }^{3}\right)^{1 / 3}
$$

while $\mathrm{h}_{\text {mixed }}$ can be found from a local heat balance

$$
\mathrm{h}_{\text {mixed }}=\frac{\mathrm{q}_{\text {gen }}-2 \cdot \mathrm{q}_{\mathrm{rad}}-\mathrm{q}_{\mathrm{nc}}}{\mathrm{T}_{\mathrm{s}}-\mathrm{T}_{\infty}}
$$

A thermocouple placed at the center of the back enclosure wall provides the ambient temperature $\mathrm{T}_{\infty}$. Data from each experiment are captured only after thermal equilibrium is reached between the heated air inside the enclosure and conditions outside the enclosure.

The lateral conduction along the foil was shown in [18] to be small compared to the overall heat generation and is neglected. The overall experimental uncertainty in measuring the heat transfer coefficient is estimated to be approximately $\pm 8 \%$ [18].

As the goal of this paper is to experimentally characterize the significance of the various geometric and operating parameters, a number of different fans were tested. Two geometric parameters under investigation, the fan width (D), and exposed blade length (L), are illustrated in Fig. 1. In addition, the two operational parameters of importance are vibration frequency $(\omega)$ and oscillation amplitude (A). The influence of a fifth parameter, the gap $(\mathrm{G})$ between the fan tip and heated target, is also investigated. It should be noted that for a given fan, three of the parameters length, width and resonance frequency - are fixed, since $\omega$ is tied to the geometry and material properties (e.g., modulus of elasticity) of the beam and the piezoelectric element. For the remaining two parameters (amplitude and gap), multiple values can be achieved by adjusting the magnitude of the input voltage signal (to change the amplitude) or moving the fan closer or farther away from the heated surface. A total of six fans of different geometries were individually tested over a range of vibration amplitudes and gaps as given in Table 1. Of these, Fan 1 is the same as that tested in [18], but additional vibration amplitudes are considered here for this fan. The ranges of fan width, exposed blade length, and frequency, represented with this set of fans are $6.35-25.4$ $\mathrm{mm}, 14.9-36.5 \mathrm{~mm}$, and $61.7-256.2 \mathrm{~Hz}$, respectively. Along with the different gaps and amplitudes considered, this yields a total of 160 experiments that were conducted in order to characterize the thermal performance of a vibrating cantilever. 


\section{Experimental Results}

The experimental results are presented in this section in terms of the local heat transfer coefficient $\left(\mathrm{h}_{\mathrm{pz}}\right)$. First, the data from the full-field heat transfer maps are presented and are followed by an analysis of profiles along linear traces across the surface for initial assessment of the influence of the governing parameters.

\subsection{Local Heat Transfer Maps}

The local convection coefficients are computed on a pixel-by-pixel basis for each infrared image, yielding 160 different maps. The general behavior observed for a piezoelectric fan at different gaps was reported in [18], and results obtained in the present work are consistent with those findings, namely that a lobed pattern in the heat transfer map is produced when the gap is small, which transitions to a nearly circular pattern for intermediate gaps, and finally becomes elliptical at large gaps. It was also noted in [18] that if the vibration amplitudes became too small, the behavior began to deviate from these characteristics.

Convection coefficient distributions are shown for Fans 2, 3, and 4 in Fig. 3, Fig. 4, and Fig. 5, respectively. Only results from the maximum amplitude are shown for each case $(6.5 \mathrm{~mm}$ for Fan 2, and $6.0 \mathrm{~mm}$ for Fan 3 and 4). In each plot, the vibration envelope is superimposed on the image and its dimensions are twice the vibration amplitude (2A) in the horizontal direction and equal to the fan width in the vertical direction. The vertical line in the center represents the fan at its zero, or undisplaced, position. These three fans are nearly identical in all respects except for the fan width, and thereby provide rough gauge for determining the influence of fan width. The same scale is used in all three figures in order to readily compare all nine plots. The contours are presented at three gaps for each fan such that the three distinct behaviors (lobed, circular, and elliptical) are apparent. It is seen that the convection coefficient magnitude is greatest when the fan is close to the heat source (part (a) of all three figures) and drops as the gap increases. Although the contours transition as expected for close, intermediate, and large gaps, the actual gaps at which these transitions occur depend on the fan width. For comparison, the three gaps for Fan 2 (G/A = 0.1, 0.75, and 2.75) are larger than those for Fan $3(\mathrm{G} / \mathrm{A}=0.05,0.3$, and 0.75) and smaller than those from Fan $4(\mathrm{G} / \mathrm{A}=0.5,2.0$, and 3.75). Therefore, the gap at which a certain distribution is realized is highly dependent on the fan width, when all other variables are held fixed. If a particular distribution were desired, then a wider fan would require a larger gap in order to produce this distribution.

It is also interesting to note that when similar heat transfer coefficient contours are realized for different fans, the magnitudes of the convection coefficients are similar. This is apparent when 
comparing the performance across Fig. 3 through Fig. 5 for any particular contour (e.g., the elliptical patterns of Fig. 3(c) have approximately the same overall magnitude as the elliptical patterns in Fig. 4(c) or Fig. 5(c)). Therefore, while the gaps at which certain distributions are realized are highly sensitive to the fan width, the actual magnitude of the performance can be described solely based on the contour shape produced, irrespective of the fan width.

\subsection{Centerlines Traces}

Quantitative comparison of the convection coefficients is facilitated by considering the thermal profiles along the horizontal $(\mathrm{y}=0)$ and vertical centerlines $(\mathrm{x}=0)$ of the heated surface. Centerline traces from the elliptical patterns for Fans 2, 3 and 4, found in Fig. 3(c), Fig. 4(c), and Fig. 5(c) are presented in Fig. 6 (a) and (b) for the vertical and horizontal centerlines, respectively. All these fans operate at nearly the same frequency, and have similar lengths and achievable amplitudes; therefore the effect of fan width may be deduced from this comparison. The distances in this figure are normalized by the amplitude in order to account for the fact that the amplitude of Fan $2(\mathrm{~A}=6.5 \mathrm{~mm})$ is slightly higher than that of Fans 3 and $4(\mathrm{~A}=6.0 \mathrm{~mm})$. From Fig. $6(\mathrm{a})$ and (b), it is again apparent that the stagnation convection coefficient is approximately equal for all three fans $\left(89.0\right.$ to $\left.89.5 \mathrm{~W} / \mathrm{m}^{2} \mathrm{~K}\right)$. The vertical centerline traces in Fig. 6 (a) also suggest that the rate at which the convection coefficient drops from its stagnation value becomes steeper as the fan width becomes smaller. The crosses superimposed on each curve of Fig. 6 (a) correspond to the top and bottom edges of the vibration envelope for each fan $(y=D / 2$ and $y=-D / 2$, for the uppermost and lowermost edges of the fan, respectively). It is interesting to note that at these locations $(y= \pm D / 2)$, the performance is lowest for the widest fan (Fan 5). However, due to the increased width, the relative influence of the fan as seen by the heated surface is greater for a wider fan, evident by the rate at which the convection coefficient drops from its stagnation value. This is also observed in the horizontal centerline traces shown in Fig. 6 (b).

Two important conclusions may be drawn from these two plots, which represent elliptical contours for three fans of different widths. First, the magnitude of the convection coefficients within the vibration envelope is a function of the shape of the contours. Being able to express the thermal performance as a function of contour shape removes the fan width as a variable from the analysis and suggests that a simplified, two-dimensional analysis could satisfactorily account for the heat transfer in this situation. The second conclusion is that, for heat transfer in regions outside the vibration envelope, the width does become an important parameter, thus necessitating an accounting of three-dimensional effects. 


\section{Analysis of Results}

The results are now further analyzed through the use of dimensionless quantities. The applicable parameters which successfully describe the experimental trends are defined, followed by a discussion of stagnation region heat transfer prediction.

\subsection{Dimensionless Quantities}

As mentioned earlier, a total of five variable parameters are considered in this work: frequency $(\omega)$, amplitude (A), width (D), length (L), and gap $(\mathrm{G})$. The measured response is the heat transfer coefficient $\left(\mathrm{h}_{\mathrm{pz}}\right)$. In order to nondimensionalize $\mathrm{h}_{\mathrm{pz}}$ and $\omega$, the thermal conductivity $(\mathrm{k})$ and kinematic viscosity $(v)$ of air are also used. The Nusselt number represents the dimensionless heat transfer and is defined in this work using vibration amplitude as the length scale according to:

$$
\mathrm{Nu}=\frac{\mathrm{hA}}{\mathrm{k}}, \overline{\mathrm{Nu}}_{\mathrm{VE}}=\frac{\overline{\mathrm{h}}_{\mathrm{VE}} \cdot \mathrm{A}}{\mathrm{k}}
$$

where $\bar{h}_{\mathrm{VE}}$ is the average forced convection coefficient within the vibration envelope defined by:

$$
\overline{\mathrm{h}}_{\mathrm{VE}}=\frac{1}{2 \mathrm{AD}}\left[\int_{-\mathrm{A}}^{\mathrm{A}}\left(\int_{-\mathrm{D} / 2}^{\mathrm{D} / 2} \mathrm{~h}_{\mathrm{pz}} \mathrm{dy}\right) \mathrm{dx}\right]
$$

$\overline{\mathrm{Nu}}_{\mathrm{VE}}$ is used in place of the stagnation Nusselt number, since for any practical application of a piezofan in the orientation considered in this paper, the area contained within the vibration envelope represents the smallest area of interest. The Reynolds number is based on the maximum tip velocity ( $\omega \cdot \mathrm{A})$ and, like the Nusselt number, uses amplitude as the length scale:

$$
\operatorname{Re}=\frac{\omega \mathrm{A}^{2}}{v}
$$

An additional parameter often used in oscillating flows is the Strouhal number, typically describing the vortex shedding from uniform flow over a bluff body. In this work, we define this parameter using a similar form as the Reynolds number, but incorporating the remaining two geometric properties of the fan according to:

$$
\operatorname{Str}=\frac{\omega \mathrm{LD}}{v}
$$

The gap is normalized by the amplitude to yield the dimensionless gap, G/A. The remainder of the paper is focused on expressing the average thermal performance within the vibration envelope.

That is, the goal is to express $\overline{\mathrm{Nu}}_{\mathrm{VE}}$ as a function of the remaining three dimensionless parameters (Re, Str, and G/A). 


\subsection{Stagnation Region Characterization}

The vibration-envelope Nusselt number ( $\left.\overline{\mathrm{Nu}}_{\mathrm{VE}}\right)$, which characterizes the behavior in the stagnation region, is plotted against G/A at different Re values for Fans 1, 2, 3, and 4 in Fig. 7 (a), (b), (c), and (d), respectively. The vertical range considered for each plot is identical $\left(5<\overline{\mathrm{Nu}}_{\mathrm{VE}}<\right.$ 30 ), and the G/A range of each plot is different depending on the gap required to produce the different contours, as previously discussed. A family of curves is presented for each plot at different Re values representing the amplitudes considered for each fan. For any given curve, the thermal contours transition from being lobed at small G/A values to elliptical at large G/A values. Therefore, bycomparing the G/A ranges in Fig. 7 for the different fans, the fan width can be seen to be highly influential in determining the gap at which a certain convection pattern will appear. The plot for the widest fan (Fan 4 in Fig. 7 (d)), which has a width of $\mathrm{D}=25.4 \mathrm{~mm}$, shows that G/A = 6 is required to realize elliptical contours. By way of comparison, plots for Fan 2 and 3 (Fig. 7 (b) and (c), respectively) show that the gaps needed to yield elliptical contours become smaller as the width is decreased (G/A of 5 for $\mathrm{D}=12.7 \mathrm{~mm}$, and $\mathrm{G} / \mathrm{A}=2$ for $\mathrm{D}=6.35 \mathrm{~mm}$ ). For Fan 1 (Fig. 7 (a)), this gap is $\mathrm{G} / \mathrm{A}=2$ and is approximately the same as that of Fan 3 (Fig. 7 (c)). While the lengths of these two fans are different, the frequency of Fan 3 is approximately twice that of Fan 1, while its width is half as much (see Table 1). This suggests that the relationship between G/A and the rate at which $\overline{\mathrm{Nu}}_{\mathrm{VE}}$ drops is nearly equally dependent on fan frequency and width.

Also apparent from the four plots in Fig. 7 is that the overall magnitude of $\overline{\mathrm{Nu}}_{\mathrm{VE}}$ increases with Re, which merely suggests that the thermal performance is higher for larger amplitudes, as might be expected. A total of five amplitudes are considered for Fan 1, therefore five curves are shown in Fig. 7 (a). As the data progresses from left to right along these curves, the thermal contours transition from lobed, to circular, and finally to elliptical patterns. In addition, the overall magnitude of the heat transfer coefficient can generally be assumed to decrease as G/A becomes large. Many of the curves exhibit an optimum gap some distance away from the heat source, with a smaller or larger gap causing a decrease in $\overline{\mathrm{Nu}}_{\mathrm{VE}}$. However, regardless of what G/A value produces the maximum performance for a particular $\mathrm{Re}$, the $\overline{\mathrm{Nu}}_{\mathrm{VE}}$ at that point represents the maximum amount of cooling that a particular fan can provide for a fixed fan geometry, frequency, and amplitude. This peak value will be referred to as $\overline{\mathrm{Nu}}_{\mathrm{VE}(\max )}$ and the behavior of this quantity is tracked for determining the factors which play a large role in predicting the best possible heat transfer rates for a particular fan design. The existence of an optimum gap was experimentally observed in a previous study [18] and is attributed to the balance between imparting kinetic energy to the fluid and overcoming additional friction and damping from the surrounding fluid as the fan vibrates near a surface. 
The $\overline{\mathrm{Nu}}_{\mathrm{VE}(\max )}$ values from each curve are plotted against Re in Fig. 8 over the entire frequency and amplitude ranges considered in this work. Interestingly, all the data collapse on the following single curve, confirming that the Reynolds number defined in this work is indeed the appropriate parameter for assessing the thermal performance:

$$
\overline{\mathrm{Nu}}_{\mathrm{VE}(\max )}=\mathrm{C}_{1}(\mathrm{Re})^{\mathrm{q}}
$$

where $\mathrm{C}_{1}$ and $\mathrm{q}$ are constants determined from a least squares analysis of the data. This yields $\mathrm{C}_{1}=$ 0.068 and $\mathrm{q}=0.78$, which result in mean and maximum deviations of $6.6 \%$ and $22 \%$, respectively. Substituting the definitions for $\overline{\mathrm{Nu}}_{\mathrm{VE}(\max )}$ and Re, the maximum possible heat transfer coefficient for each combination of amplitude and frequency can be expressed as:

$$
\mathrm{h}_{\mathrm{VE}(\max )}=0.068 \mathrm{k}\left(\frac{\omega}{v}\right)^{0.78} \mathrm{~A}^{0.56}
$$

For a fan operating at the optimum gap, the problem thus becomes two-dimensional in nature, since the fan width and length do not factor into this expression. The width and length do affect the location of the optimum gap, but the maximum cooling a given fan can deliver is only a function of $\omega$ and $\mathrm{A}$, the two defining vibration characteristics.

It is interesting to compare this result with that from [9], where the convection coefficients were characterized for a heated cylinder vibrating at different frequencies and amplitudes. The Nusselt and Reynolds numbers were defined in a similar manner in [9]. Their findings suggest an almost identical scaling relationship, namely that $\mathrm{Nu} \sim \mathrm{Re}^{3 / 4}$. It is also noted that Eq. (10) suggests that the frequency is more influential than the amplitude in determining the attainable heat transfer rates. For example, if the frequency was increased by $30 \%$, the resulting thermal performance would be $22 \%$ higher, whereas the same $30 \%$ increase in vibration amplitude would only provide a $15 \%$ increase. It is difficult in practice to simultaneously increase the frequency and amplitude. The trade-off between these two parameters can therefore by informed by the expression in Eq. (10).

The curves in Fig. 7 as well as those for Fans 2 and 6 (one amplitude each) are now normalized by their respective $\overline{\mathrm{Nu}}_{\mathrm{VE}(\max )}$ values. The dependence of this normalized Nusselt number $\left(\overline{\mathrm{Nu}}_{\mathrm{VE}} / \overline{\mathrm{Nu}}_{\mathrm{VE}(\max )}\right)$ on gap is found to be well described by an exponential decay and the fan geometry $(D, L)$ is accounted for through use of the Strouhal number (Str from Eq. (8)), which also includes the frequency. Therefore, an expression of the following form was employed to predict this behavior:

$$
\frac{\overline{\mathrm{Nu}}_{\mathrm{VE}}}{\overline{\mathrm{Nu}}_{\mathrm{VE}(\max )}}=\mathrm{C}_{2}\left[\exp \left(\mathrm{C}_{3} \frac{\mathrm{G}}{\mathrm{A}} \frac{1}{\mathrm{Str}}\right)\right]
$$


The result of this analysis is shown in Fig. 9 with $\mathrm{C}_{2}=1.08$ and $\mathrm{C}_{3}=-2560$ obtained from a leastsquares analysis, which yields mean and maximum deviations of $8.9 \%$ and $27 \%$, respectively. Again, the results for all the different fans collapse on to a single curve, suggesting that the simple functional forms in Eqs. (9) and (11) are successful in describing the complicated fluid-thermal phenomena involved in the use of vibrating cantilevers for cooling purposes. Both equations also obtain physically realistic limits: as $\mathrm{D} \rightarrow 0, \mathrm{~A} \rightarrow 0$, or $\mathrm{G} \rightarrow \infty, \overline{\mathrm{Nu}}_{\mathrm{VE}}$ and $\overline{\mathrm{Nu}}_{\mathrm{VE}(\max )} \rightarrow 0$ (i.e., heat transfer performance approaches zero). Finally, for all the experiments presented here, the optimum gap $\left(\mathrm{G}_{\mathrm{opt}} / \mathrm{A}\right)$ for maximizing the thermal performance falls in the range:

$$
0.1(\mathrm{Str}) \times 10^{-4}<\frac{\mathrm{G}_{\mathrm{opt}}}{\mathrm{A}}<0.5(\mathrm{Str}) \times 10^{-4}
$$

Taking the optimum value to fall approximately in the middle of this range $\left(\frac{\mathrm{G}_{\mathrm{opt}}}{\mathrm{A}} \approx 0.3(\mathrm{Str}) \times 10^{-4}\right)$, the dependence on width and length is readily observed after substituting the Strouhal number definition (Eq. (8)) into Eq. (12), which yields $\frac{\mathrm{G}_{\mathrm{opt}}}{\mathrm{A}} \square \omega^{1}, \mathrm{~L}^{1}, \mathrm{D}^{1}$. In other words, the optimum gap is linearly dependent on frequency, length, and width. For example, an increase of $10 \%$ in any one of these parameters $(\omega, \mathrm{L}$, or $\mathrm{D})$ is predicted to cause a $10 \%$ increase in the optimum gap value. Likewise, the presence of the Strouhal number in Eq. (11) reveals the influence of these same three variables on the rate at which the performance exponentially decays from its optimum value as the gap is increased. This decay rate, defined as $\gamma=\frac{\mathrm{G}}{\mathrm{A}} \frac{1}{\mathrm{Str}}$ from Eq. (11), suggests an inverse proportionality with $\mathrm{Str}$ for the decay rate (i.e., $\left.\gamma \square \omega^{-1}, \mathrm{~L}^{-1}, \mathrm{D}^{-1}\right)$. Therefore, an increase in either frequency, length, or width will cause a decrease in the rate at which the performance drops from its optimum value, effectively creating a larger window of over which optimum or near-optimum conditions exist. Further constraints on these governing parameters may be dictated by the application. For example, if inaudible infrasonic frequencies are desired, then $\omega$ must be held < $60-100 \mathrm{~Hz}$.

\section{Conclusions}

The experimental investigation conducted in this work has enabled an identification of the appropriate dimensionless parameters which influence the heat transfer rates from the flows generated by vibrating cantilevers. The experiments consider the influence of each important variable (fan length, width, gap, frequency, and amplitude) and support the development of a comprehensive model to predict the thermal performance of generalized piezoelectric fans. Key physical insights and results from this work include: 
1) The maximum performance for a given fan can be described in terms of the vibration frequency and oscillation amplitude only.

2) The frequency is found to be somewhat more influential than the amplitude in determining the largest attainable heat transfer rates.

3) The width, length, and frequency, each exhibit the same influence on the value of optimum gap $\left(\mathrm{G}_{\mathrm{opt}} / \mathrm{A}\right)$ and the exponential decay rate from the peak performance $(\gamma)$.

4) Proposed correlations for predicting heat transfer rates describe the thermal performance within the vibration envelope of all the fans over the entire frequency and amplitude range tested for $500<\operatorname{Re}<2500$ and $0.3 \times 10^{-4}<\left(\frac{G}{\text { A Str }} \frac{1}{\text { St }}\right)<3.5 \times 10^{-4}$.

\section{Acknowledgements}

The authors acknowledge the financial support from members of the Cooling Technologies Research Center, a National Science Foundation Industry/University Cooperative Research Center at Purdue University. We are grateful to Dr. Ioan Sauciuc of Intel Corporation for providing the fans for the experiments.

\section{References}

[1] D. H. Kim, Y. H. Lee, and S. H. Chang, Effects of mechanical vibration on critical heat flux in vertical annulus tube, Nuclear Engineering and Design, 273 (2007) 982-987.

[2] T. Hibiki, and M. Ishii, Effect of flow-induced vibrations on local flow parameters of two-phase flow, Nuclear Engineering and Design, 185 (1998) 113-125.

[3] A. Klaczak, Report from experiments on heat transfer by forced vibrations of exchangers, Heat and Mass Transfer, 32 (1997) 477-480.

[4] M. Kaviany, Performance of a heat exchanger based on enhanced heat diffusion in fluids by oscillation: Analysis, ASME Journal of Heat Transfer, 112 (1990) 49-55.

[5] M. Kaviany, and M. Reckker, Performance of a heat exchanger based on enhanced heat diffusion in fluids by oscillation: Experiment, ASME Journal of Heat Transfer, 112 (1990) 56-63.

[6] R. S. Alassar, H. M. Badr, and H. A. Mavromatis, Heat convection from a sphere placed in an oscillating free-stream, International Journal of Heat and Mass Transfer, 42 (1999) 1289-1304.

[7] M. Y. Ha, S. Yavuzkurt, and K. C. Kim, Heat transfer past particles entrained in an oscillating flow with and without a steady velocity, International Journal of Heat and Mass Transfer, 36 (1993) 949-959.

[8] H. Iwai, T. Mambo, N. Yamamoto, K. Suzuki, Laminar convective heat transfer from a circular cylinder exposed to a low frequency zero-mean velocity oscillating flow, International Journal of Heat and Mass Transfer, 47 (2004) 4659-4672. 
[9] A. Gopinath, and D. R. Harder, An experimental study of heat transfer from a cylinder in low-amplitude zero-mean oscillatory flows, International Journal of Heat and Mass Transfer, 43 (2000) 505-520.

[10] X. R. Zhang, S. Murayama, and S. Sakai, Numerical investigation of laminar natural convection on a heated vertical plate subjected to a periodic oscillation, International Journal of Heat and Mass Transfer, 47 (2004) 4439-4448.

[11] H. Gomaa, and A. M. Al Taweel, Effect of oscillatory motion on heat transfer at vertical flat surfaces, International Journal of Heat and Mass Transfer, 48 (2005) 1494-1504.

[12] M. Toda, Theory of air flow generation by a resonant type $\mathrm{PVF}_{2}$ bimorph cantilever vibrator, Ferroelectrics, 22 (1979) 911-918.

[13] M. Toda, Voltage-induced large amplitude bending device - $\mathrm{PVF}_{2}$ bimorph - its properties and applications, Ferroelectrics, 32 (1981) 127-133.

[14] T. Açıkalın, S. M. Wait, S. V. Garimella, and A. Raman, Experimental investigation of the thermal performance of piezoelectric fans, Heat Transfer Engineering, 25 (2004) 4-14.

[15] T. Açikalın, S. V. Garimella, A. Raman, and J. Petroski, Characterization and optimization of the thermal performance of miniature piezoelectric fans, International Journal of Heat and Fluid Flow, 28(4) (2007) 806820.

[16] T. Açıkalın, I. Sauciuc, and S. V. Garimella, Piezoelectric actuators for low-form factor electronics cooling, Proceedings of the ASME InterPACK Conference, San Francisco, CA, 2 (2005) 939-943.

[17] M. Kimber, K. Suzuki, N. Kitsunai, K. Seki, and S.V. Garimella, Quantification of piezoelectric fan flow rate performance and experimental identification of installation effects, Inter Society Conference on Thermal Phenomena, Orlando, FL, 2008.

[18] M. Kimber, S. V. Garimella, and A. Raman, Local heat transfer coefficients induced by piezoelectrically actuated vibrating cantilevers, ASME Journal of Heat Transfer, 129 (2007) 1168-1176.

[19] M. Kimber, and S.V. Garimella, Cooling performance of arrays of vibrating cantilevers, ASME Journal of Heat Transfer, (in press).

[20] L. A. Florio, and A. Harnoy, Combination technique for improving natural convection cooling in electronics, International Journal of Thermal Sciences, 46 (2007) 76-92.

[21] L. A. Florio, and A. Harnoy, Augmenting natural convection in a vertical flow path through transverse vibrations of an adiabatic wall, Numerical Heat Transfer Part A-Applications, 52 (2007) 497-530.

[22] S.J. Yang, A numerical investigation of heat transfer enhancement for electronic devices using an oscillating vortex generator, Numerical Heat Transfer Part A-Applications, 42 (2002) 269-284.

[23] T. Wu, and P.I. Ro, Heat transfer performance of a cooling system using vibrating piezoelectric beams, J. Micromech. Microeng., 15 (2005) 213-220.

[24] NASA Jet Propulsion Laboratory Web Site, URL: http://masterweb.jpl.nasa.gov/reference/paints.htm [25] F. Incropera, and D. DeWitt, Fundamentals of Heat and Mass Transfer, fifth ed., Wiley, New York, 2002. 


\section{List of Figures}

Fig. 1. Illustration of piezoelectric fan showing important geometric parameters: overall blade length (L0), exposed blade length (L), and fan width (D).

Fig. 2. Flux balance on constant heat flux surface.

Fig. 3. Convection coefficient (hpz) maps for Fan 2 with G/A = 0.1, 0.75, and 2.75 for (a), (b), and (c) respectively. The vibration amplitude is $6.5 \mathrm{~mm}$ and the size of the heater shown is $150 \times 100 \mathrm{~mm}$.

Fig. 4. Convection coefficient (hpz) maps for Fan 3 with G/A = 0.05, 0.3, and 0.75 for (a), (b), and (c) respectively. The vibration amplitude is $6.0 \mathrm{~mm}$ and the size of the heater shown is $150 \times 100 \mathrm{~mm}$.

Fig. 5. Convection coefficient (hpz) maps for Fan 4 with $\mathrm{G} / \mathrm{A}=0.5,2.0$, and 3.75 for (a), (b), and (c) respectively. The vibration amplitude is $6.0 \mathrm{~mm}$ and the size of the heater shown is $150 \mathrm{x} 100 \mathrm{~mm}$.

Fig. 6. Centerline traces extracted from the elliptical patterns in Fig. 3 (c), Fig. 4 (c), and Fig. 5 (c) in the (a) vertical direction, and (b) horizontal direction. Crosses superimposed on (a) correspond to $y= \pm D / 2$ for each fan. Gaps for both plots are $\mathrm{G} / \mathrm{A}=2.75,0.75$, and 4.75 for fans 2,3 , and 4 , respectively.

Fig. 7. Vibration-envelope Nusselt numbers for (a) Fan 1, (b) Fan 2, (c) Fan 3, and (d) Fan 4 at three different Reynolds numbers each.

Fig. 8. Maximum vibration envelope Nusselt numbers ( $\left.\overline{\mathrm{Nu}}_{\mathrm{VE}(\max )}\right)$ for six fans (Table 1), representing a wide range of frequencies and geometries. The curve fit shown is defined in Eq. (9).

Fig. 9. $\overline{\mathrm{Nu}}_{\mathrm{VE}}$ normalized by its maximum value $\left(\overline{\mathrm{Nu}}_{\mathrm{VE}} / \overline{\mathrm{Nu}}_{\mathrm{VE}(\max )}\right)$ for six different fans (Table 1). The curve fit shown is defined in Eq. (11). 
Table 1. List of experimental parameters for six fans used to assess thermal performance.

\begin{tabular}{|c|c|c|c|c|c|c|c|}
\hline Fan No. & $\begin{array}{c}\text { Blade } \\
\text { Material }\end{array}$ & $\mathbf{D}[\mathrm{mm}]$ & $\mathbf{L}[\mathbf{m m}]$ & $\omega[\mathrm{Hz}]$ & $\mathbf{A}[\mathbf{m m}]$ & G/A & $\begin{array}{c}\text { \# of } \\
\text { experiments }\end{array}$ \\
\hline 1 & Mylar & 12.7 & 36.5 & 61.7 & $\begin{array}{c}5-10 \\
(5 \text { values })\end{array}$ & $\begin{array}{c}0.01-2.0 \\
(10 \text { values })\end{array}$ & 50 \\
\hline 2 & $\begin{array}{l}\text { Stainless } \\
\text { Steel }\end{array}$ & 12.7 & 23.1 & 126.5 & $\begin{array}{l}4.5-6.5 \\
(3 \text { values })\end{array}$ & $\begin{array}{c}0.1-5.0 \\
(10 \text { values })\end{array}$ & 30 \\
\hline 3 & $\begin{array}{l}\text { Stainless } \\
\text { Steel }\end{array}$ & 6.35 & 23.5 & 128.5 & $\begin{array}{c}4.5-6.0 \\
(3 \text { values })\end{array}$ & $\begin{array}{c}0.01-2.0 \\
(10 \text { values })\end{array}$ & 30 \\
\hline 4 & $\begin{array}{l}\text { Stainless } \\
\text { Steel }\end{array}$ & 25.4 & 24.2 & 129.3 & $\begin{array}{l}4.5-6.0 \\
(3 \text { values })\end{array}$ & $\begin{array}{c}0.2-6.0 \\
(10 \text { values })\end{array}$ & 30 \\
\hline 5 & $\begin{array}{c}\text { Stainless } \\
\text { Steel }\end{array}$ & 6.35 & 14.9 & 256.2 & 2.5 & $\begin{array}{c}0.01-2.0 \\
(10 \text { values })\end{array}$ & 10 \\
\hline 6 & Mylar & 12.7 & 28.1 & 100.1 & 3 & $\begin{array}{c}0.01-2.0 \\
(10 \text { values })\end{array}$ & 10 \\
\hline
\end{tabular}




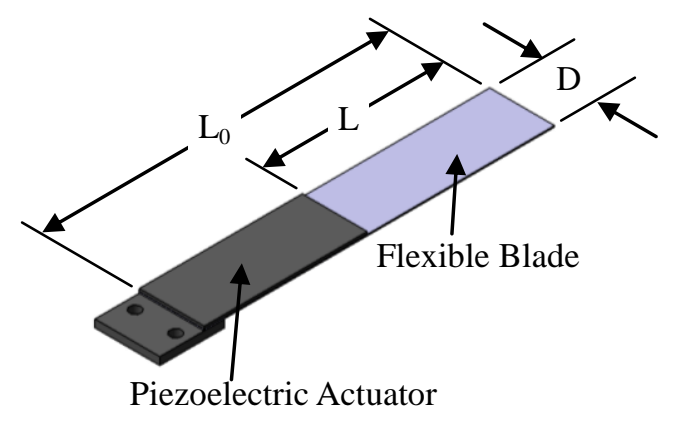

Fig. 1. Illustration of piezoelectric fan showing important geometric parameters: overall blade length $\left(L_{0}\right)$, exposed blade length $(L)$, and fan width (D). 


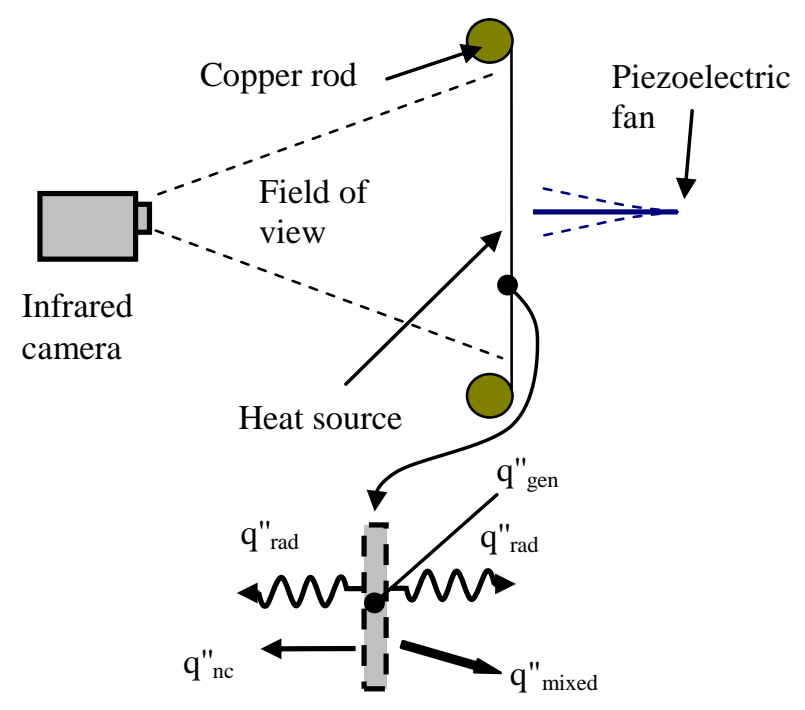

Fig. 2. Flux balance on constant heat flux surface. 


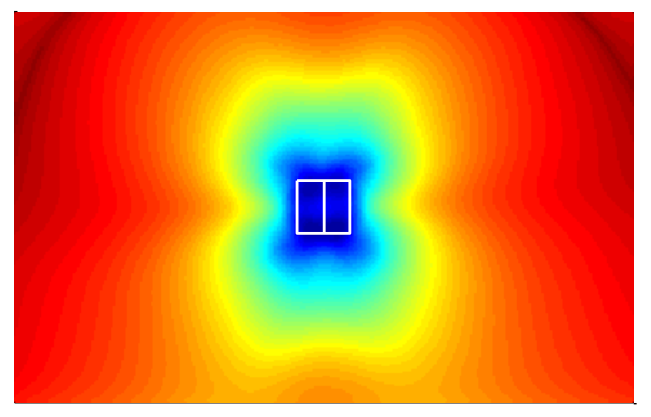

$\mathrm{W} / \mathrm{m}^{2} \mathrm{~K}$
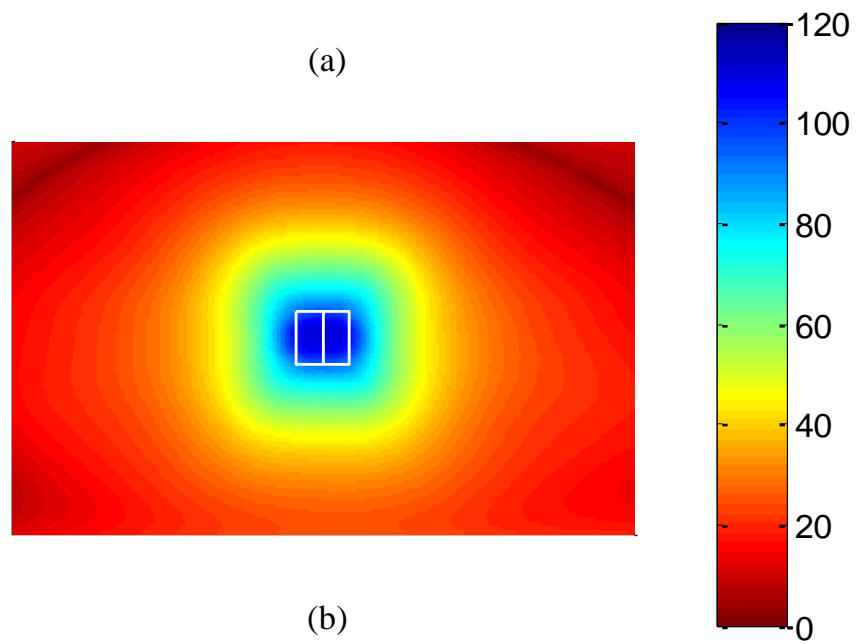

(b)

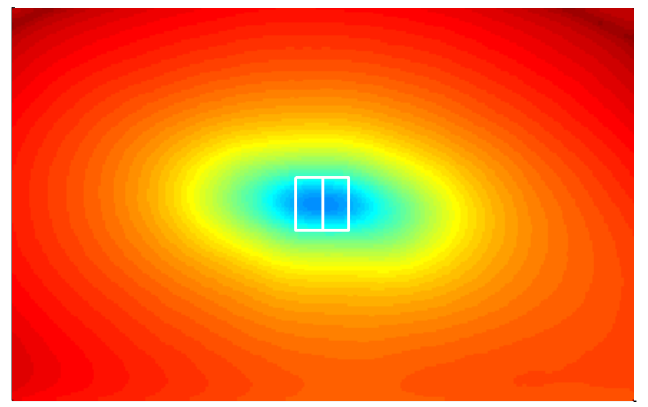

(c)

Fig. 3. Convection coefficient $\left(h_{p z}\right)$ maps for Fan 2 with $G / A=0.1,0.75$, and 2.75 for $(a)$, (b), and (c) respectively. The vibration amplitude is $6.5 \mathrm{~mm}$ and the size of the heater shown is $150 \times 100 \mathrm{~mm}$. 


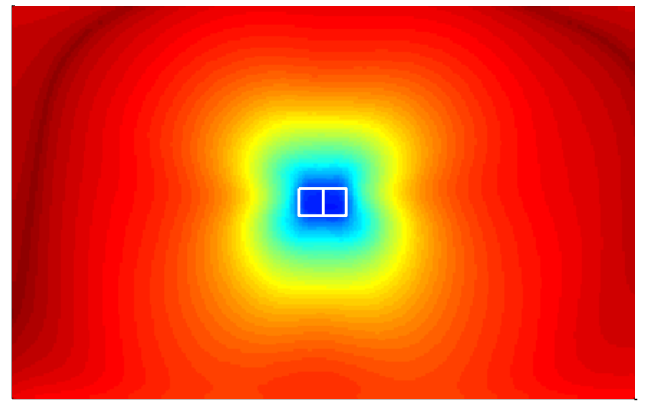

$\mathrm{W} / \mathrm{m}^{2} \mathrm{~K}$

(a)
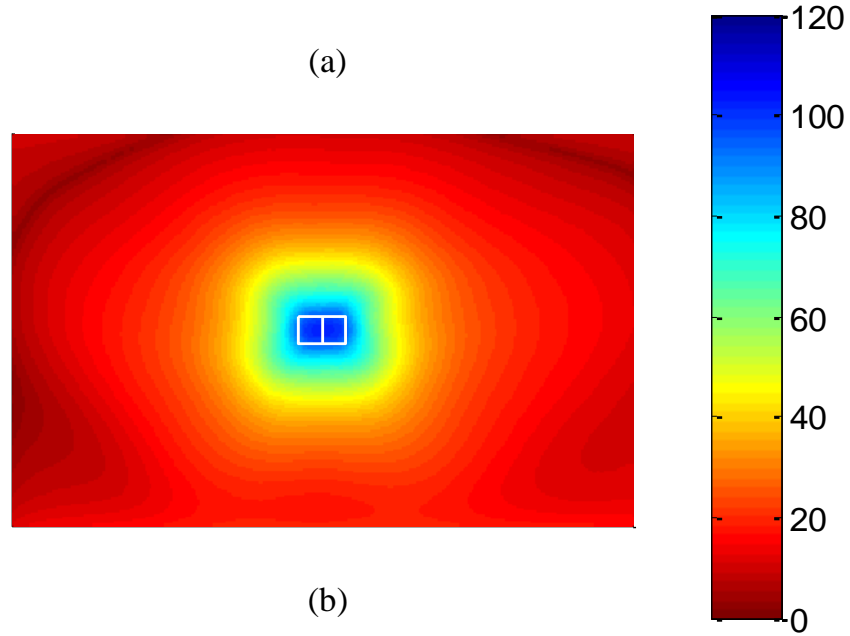

(b)

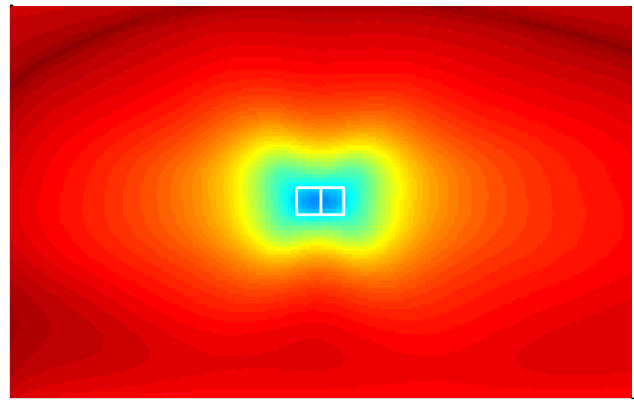

(c)

Fig. 4. Convection coefficient $\left(h_{p z}\right)$ maps for Fan 3 with $G / A=0.05,0.3$, and 0.75 for $(a),(b)$, and (c) respectively. The vibration amplitude is $6.0 \mathrm{~mm}$ and the size of the heater shown is $150 \times 100 \mathrm{~mm}$. 


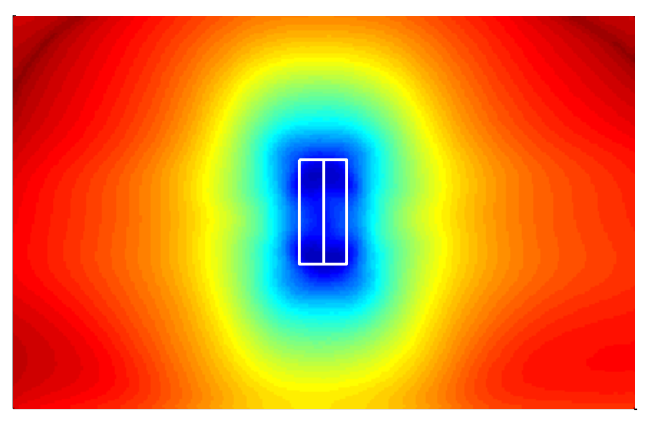

(a)

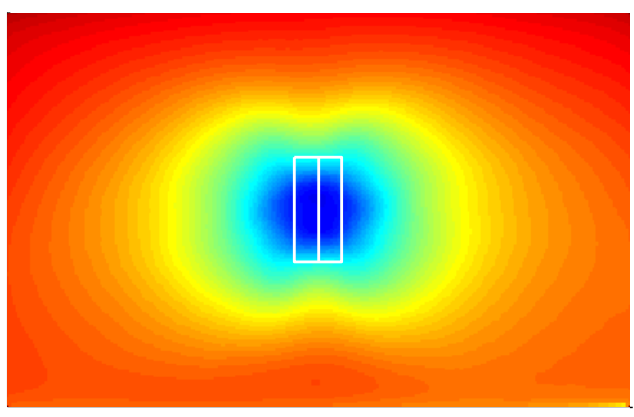

(b)

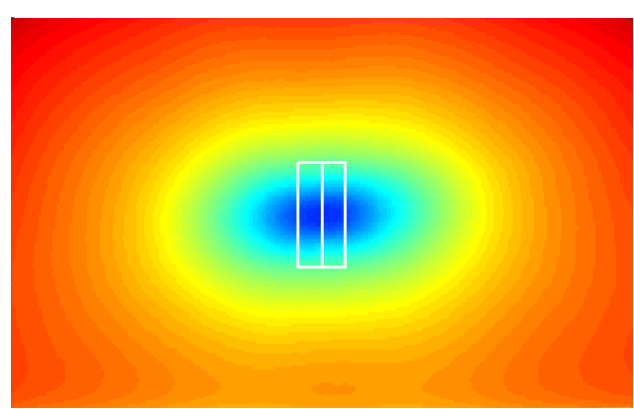

(c)
$\mathrm{W} / \mathrm{m}^{2} \mathrm{~K}$

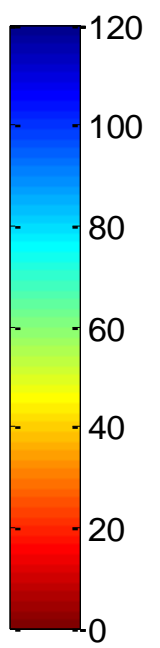

Fig. 5. Convection coefficient $\left(h_{p z}\right)$ maps for Fan 4 with $G / A=0.5,2.0$, and 3.75 for (a), (b), and (c) respectively. The vibration amplitude is $6.0 \mathrm{~mm}$ and the size of the heater shown is $150 \times 100 \mathrm{~mm}$. 


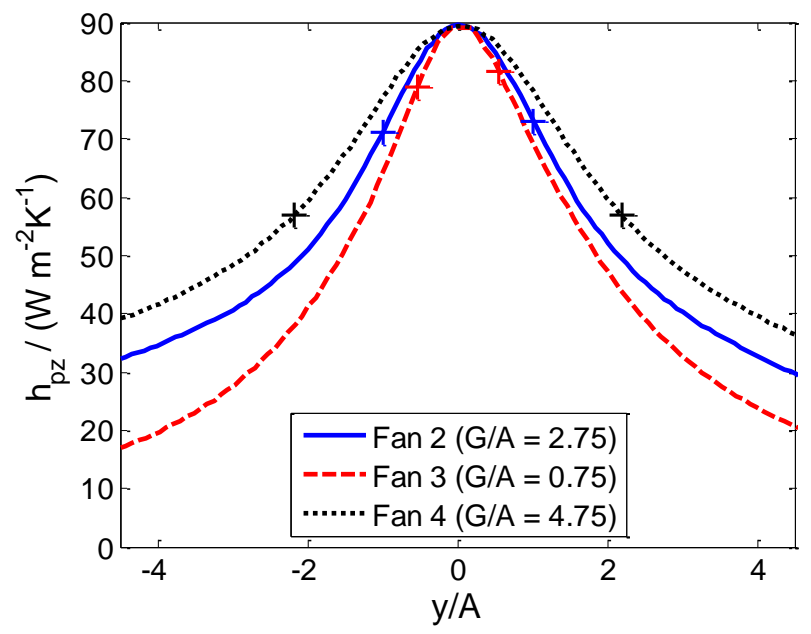

(a)

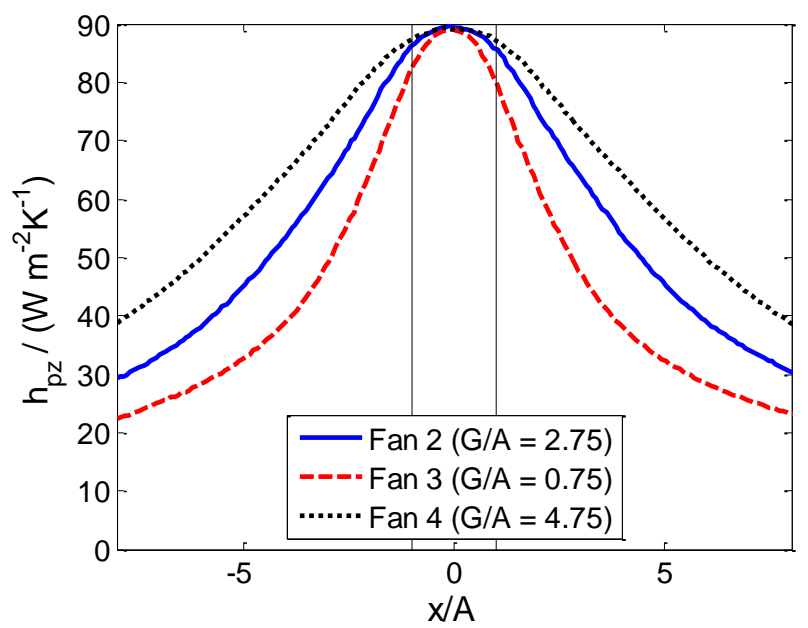

(b)

Fig. 6. Centerline traces extracted from the elliptical patterns in Fig. 3 (c), Fig. 4 (c), and Fig. 5 (c) in the (a) vertical direction, and (b) horizontal direction. Crosses superimposed on (a) correspond to $y= \pm D / 2$ for each fan. Gaps for both plots are $G / A=2.75,0.75$, and 4.75 for fans 2,3 , and 4 , respectively. 


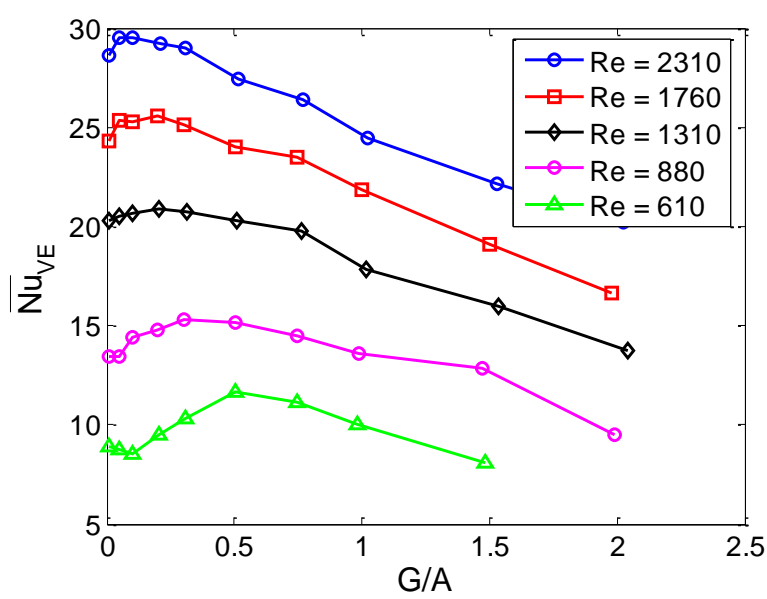

(a)

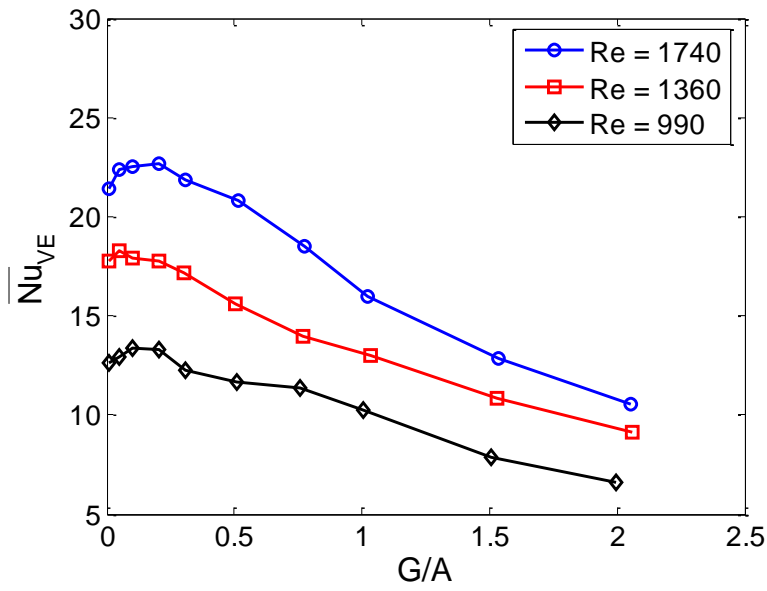

(c)

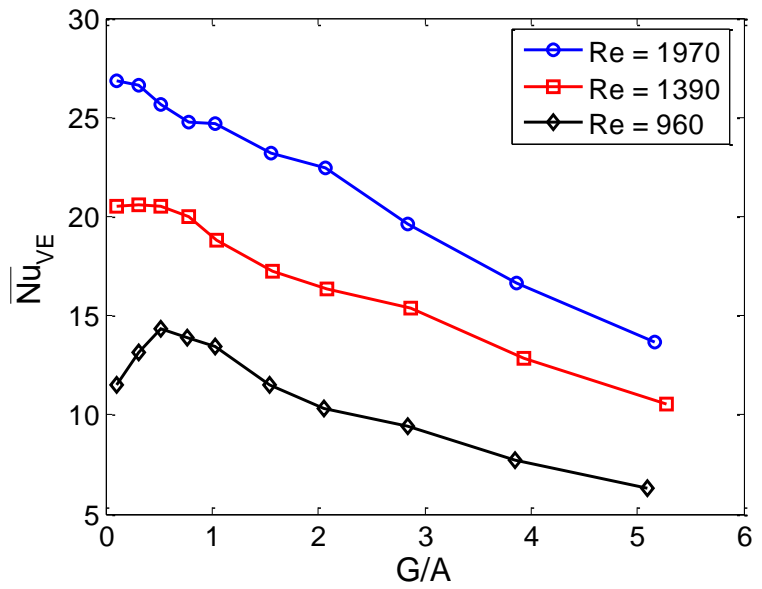

(b)

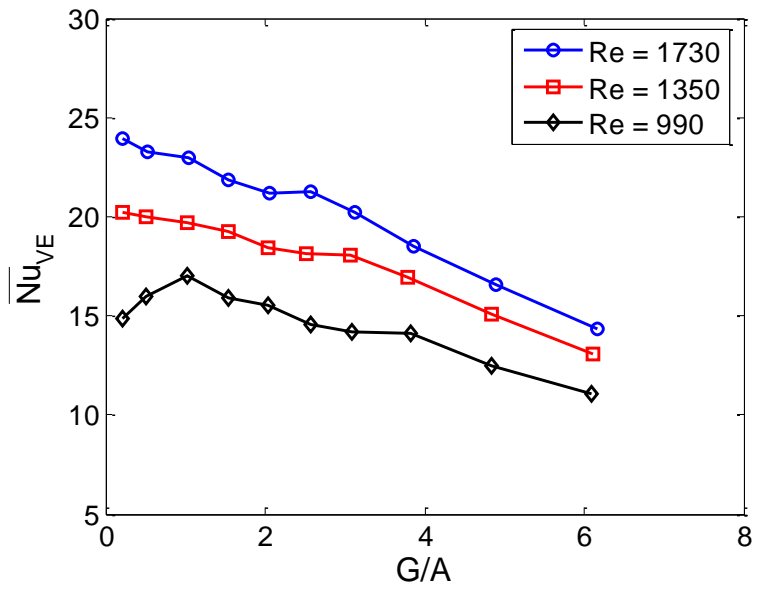

(d)

Fig. 7. Vibration-envelope Nusselt numbers for (a) Fan 1, (b) Fan 2, (c) Fan 3, and (d) Fan 4 at three different Reynolds numbers each. 


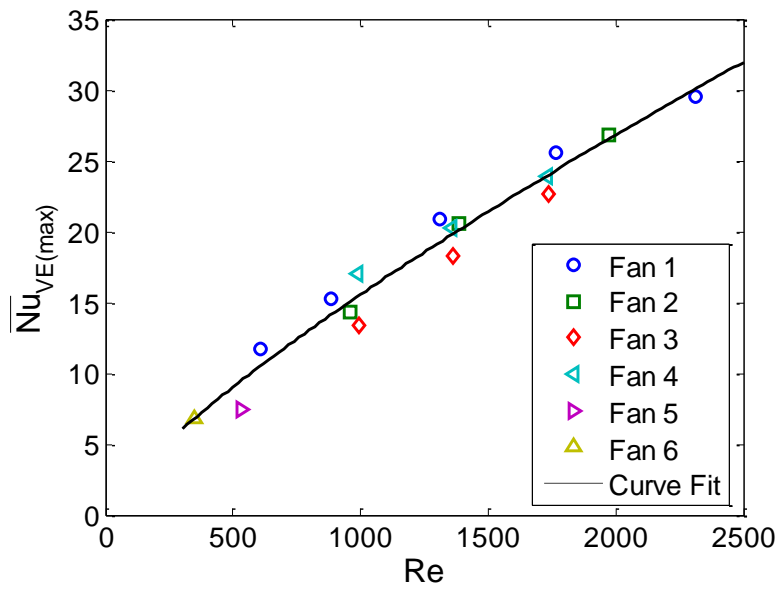

Fig. 8. Maximum vibration-envelope Nusselt numbers $\left(\overline{\mathrm{Nu}}_{\mathrm{VE}(\max )}\right)$ for six fans (Table 1), representing a wide range of frequencies and geometries. The curve fit shown is defined in Eq. (9). 


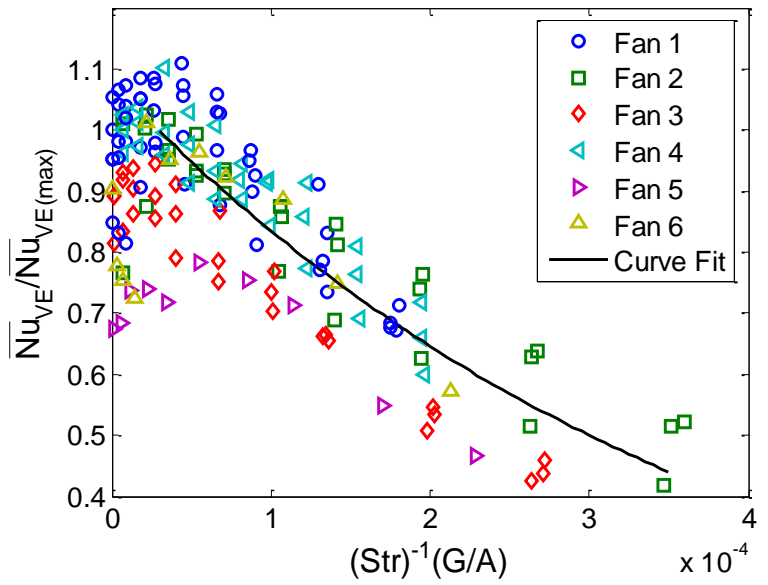

Fig. 9. $\overline{\mathrm{Nu}}_{\mathrm{VE}}$ normalized by its maximum value $\left(\overline{\mathrm{Nu}}_{\mathrm{VE}(\max )}\right)$ for six different fans (Table 1$)$. The curve fit shown is defined in Eq. (11). 